\title{
Impact of Green Construction Procurement on Achieving Sustainable Economic Growth Influencing Green Logistic Services Management and Innovation Practices
}

Tsimisaraka Raymondo Sandra Marcelline ${ }^{1 *}$, Ye Chengang ${ }^{2}$, Andrianarivo Andriandafiarisoa Ralison Ny Avotra $^{3}$, Zahid Hussain ${ }^{4}$, Josoa Eric Zonia ${ }^{5}$ and Ahsan Nawaz 6

OPEN ACCESS

Edited by:

Muhammad Mohsin, Hunan University of Humanities, Science and Technology, China

Reviewed by:

Noor UI Ain,

Quaid-i-Azam University, Pakistan Atif Ali,

University of Agriculture, Faisalabad,

Pakistan

*Correspondence:

Tsimisaraka Raymondo Sandra

Marcelline

sandra.raymondo@hgnu.edu.cn

Specialty section:

This article was submitted to

Environmental Economics and

Management,

a section of the journal

Frontiers in Environmental Science

Received: 16 November 2021

Accepted: 17 December 2021

Published: 26 January 2022

Citation:

Sandra Marcelline TR, Chengang $Y$,

Ralison Ny Avotra AA, Hussain Z, Zonia JE and Nawaz A (2022) Impact of Green Construction Procurement on

Achieving Sustainable Economic

Growth Influencing Green Logistic

Services Management and

Innovation Practices.

Front. Environ. Sci. 9:815928.

doi: 10.3389/fenvs.2021.815928
${ }^{1}$ Business School, Huanggang Normal University, Huanggang, China, ${ }^{2}$ Business School, University of International Business and Economics, Beijing, China, ${ }^{3}$ Business School, Zhejiang Wanli University, Ningbo, China, ${ }^{4}$ School of Finance, Qilu University of Technology (Shandong Academy of Sciences), Jinan, China, ${ }^{5}$ Ministry of Foreign Affairs, Antananarivo, Madagascar, ${ }^{6}$ College of Civil Engineering and Architecture, Zhejiang University, Hangzhou, China

Green construction procurement is a part of the sustainable development goals (SDGs) that influence economic growth on a strategic level. Adopting green technologies and practices has no longer been an option but a well-worth route for gaining a competitive advantage in the construction sector. The emergent concepts of green procurement and sustainability have raised the need to measure the financial performances in supply chain practices. Green procurement is now gaining importance in the construction industry and supply chain practices for a safer tomorrow. The study aimed to investigate the impact of construction procurement on green logistic services, innovation practices, and their subsequent role in gaining sustainable economic development goals. The population frame for this study was the project teams (engineers and project managers) of construction companies in China. The sampling design followed was convenient random sampling. The study was conducted using self-administered questionnaire surveys to avoid any respondent biases and/or errors. The study's findings show that construction procurement is partially associated with green logistic services management, which thoroughly determines the sustainable economic development goals. Furthermore, construction procurement is found to have a significant impact on green innovation practices that partially predict the SDGs, and the mediation of green logistic services and innovation practices are partially mediated to the construction procurement and sustainable goals. In the future, the study results will help the construction practitioners, contractors, bidders, and engineering community to shape their relationships in a greener way up or down the stream of their supply chains. Additionally, the implication of green procurement and logistic services offers many challenges in the long run for attaining SDGs; however, in the short run, it gives operational efficiency and less hazardous environmental emissions. 
Keywords: green construction procurement, green logistic services management, green innovation practices, sustainable economic development goals, procurement policies

\section{INTRODUCTION}

Our global environment is continuously deteriorating, which endorses an urgent plea for taking remedial actions to detain further damage, preventive measures to conserve the available resources, and adopting such environmentally friendly practices that minimize the supplementary hurt to the environment (Naseem et al., 2021). In developing countries, the shift to urbanization has changed the paradigm of the construction industry. To fulfill the needs of the increasing populations, massive infrastructural developments have been taking place lately that are contributing to a number of environmental issues such as pollution, emission of hazardous gases that impact the ozone layer depletion, greenhouse effect, climate change, imbalance of the ecosystem, and significant consumption of energy and other natural resources (Mohsin et al., 2021a). According to Tawfik Alqadami et al. (2020), the construction industry has been contributing majorly to environmental pollution. At the global level, activities involved in infrastructure and building developments add $40 \%$ of carbon dioxide, $30 \%$ of wastes, and $20 \%$ of pollutants to the environment (Tawfik Alqadami et al., 2020). This green approach can save future communities from facing horrendous outcomes of our current practices.

Green requirements of the businesses, including green logistic services and innovation practices, can be general or specific, preventive or facilitating, or punitive. These green logistic practices could be used either to elicit or to support the best possible opportunity available to achieve particular sustainable development goals (SDGs), which can help to achieve a climate where productivity, technological output, and innovation are promoted to obtain the desired environment-friendly results (Huo et al., 2020). Given the crucial need to enhance industrial practices, including logistics and innovation, into green, the new competitive advantage of organizations in this active and competitive era has now been diverted to eco-design, eco-production, and ecological-friendly integration through supply chains. Practicing in a safe, greener, cost-effective manner and facilitation of green procurement and logistics services management in infrastructural developments have been major concerns in the construction industry (Nawaz et al., 2019).

SDGs are the compilation of 17 objectives that are interdependent and interconnected strategies to practice sustainable solutions to today's most prevailing issues of society, economy, and environment. These goals were proposed by United Nations in 2015 as an agreement to achieve sustainability at the global level by 2030 (Nawaz et al., 2021). These SDGs consider the broader perspective of sustainability; however, the challenge for implementing those recommended practices remains a challenge. More broadly, these goals strive for the sustainability of the economic, social, and environmental perspectives. Numbers of studies have previously been carried out in pursuit of solutions to these issues. Porter and van der Linde (1995) suggested that a business's environmentfriendly design (green requirements) triggers innovation and enhances business competence. Further validation in understanding green procurement factors contributing to SDGs is needed considering green logistics services and innovation practices. Consequently, the current study has identified the gaps in the green innovation theory associating it with the SDGs adhering to green procurement and logistics services management in China's construction industry. It aims at providing an insightful exploration into some questions as 1) How is green construction procurement associated with green logistic services? 2) How do green construction procurement techniques and policies ensure green innovative practices? 3) What role does green logistic services management play in attaining the SDGs? 4) How can innovative green practices contribute to sustainable economic goals?

\section{Study Rationale}

The need for a better tomorrow calls out for the inputs from individuals, organizations, and countries in their capacities, especially the developing countries are recommended to devise their infrastructural needs carefully and urged to ensure the incorporation of sustainable green methods and material in their projects (Awan et al., 2019). This green approach can save future communities from facing horrendous outcomes of our current practices. Therefore, it has been stressed that to incorporate the greener perspective is currently prevailing practices regarding construction procurement, logistic services, and innovation efforts (Wang et al., 2017; Karaman et al., 2020; Lazaroiu et al., 2020) So, the current study has attempted understanding the possible effects of green construction procurements on logistic services management, green innovation practices, and exploring their collective contribution to the attainment of SDGs.

\section{REVIEW OF LITERATURE}

\section{Green Construction Procurement With Green Logistic Services Management}

Green procurement is the purchases or buying of the products that minimize the negative effects and maximizes the positive impacts on the environment and reduction of waste materials by embedding the concerns of recycling and replacing raw material regarding the environment into purchasing policies and strategies (Song et al., 2015; Wong et al., 2016). Logistics is the delivery of products from their origin to the final destination where they are consumed (Tan et al., 2020). This is important to integrate the process of procurement with preferences regarding the environment while purchasing raw materials, logistics services, and recycling. The use of nonrenewable resources and materials on a large scale, especially in constructing new infrastructures and 
buildings, has significantly affected the environment. The activities involved in the construction process, e.g., (manufacturing and transportation) materials that consume energy on a very large scale and emit vast amounts of greenhouse gases, are very harmful to the environment.

Furthermore, it is also necessary for organizations to be involved in procurement and logistics to estimate the financial costs of the products at its lifecycle and to assess the environmental costs, which are equally important to the purchase of raw materials, manufacturing, transporting, handling, storage, and consumption (Wong et al., 2016; Bohari et al., 2017). Green logistics has been gaining importance to improve logistic sustainability (Tan et al., 2020). According to Wong et al. (2016), green procurement considers all these factors of purchase, manufacturing, transporting, handling and storage, consumption, and finally, the disposal of products or recycling. The environmental requirements should be placed in the tenders put forward and the contracts signed to adhere to the green procurement in the construction industry. Based on prior literature, the following hypotheses have been formulated considering green procurement in logistics services management.

$\mathbf{H}_{\mathbf{1}}$ : Green procurement is positively associated with green logistic services

According to Song et al. (2015) and Wong et al. (2016), by involving greener practices in the procurement department, a higher fraction can reduce packaging and transportation costs. Greener resources are consumed at the maximum level to improve costs and environmental damage during the procurement and supply chain processes (Naseem et al., 2020; Mohsin et al., 2021b). Green policies have been found to contribute hugely to the attainment of green development through enhancing green logistics services, their effectiveness, and up-gradation (Zhang et al., 2020). Moreover, it has been suggested in the literature that nonrecyclable material should be used to the lowest degree for the packaging of products (Naseem et al., 2021; Sarfraz et al., 2021). When organizations involved in construction procurement move up the supply chain, the use of recyclable packaging material adds to the improvement of environmental sustainability.

Similarly, suppose the greener practices are declared mandatory in the procurement activities through supply chains. In that case, an improvement in the transportation of raw material or other materials involved can be seen (Song et al., 2015). In the past, Croce et al. (2019) have studied the impact of using an electric vehicle to transport the materials to make a difference to achieve sustainability in shuttling. Green procurement has caused an upsurge in the logistics services industry with the emergence of green logistic technologies that dramatically boosted green efficiency. Procurement policies, when implemented adequately, tend to involve the logistic services that sustain the environmentally friendly factor in transportation (Naseem et al., 2020). The literature mentioned earlier forms the basis for the following sub-hypotheses based on $\mathrm{H} 1$ as
$\mathbf{H}_{1 \mathbf{a}}$ : Green construction procurement techniques are positively associated with sustainable packaging of shipping materials

$\mathbf{H}_{\mathbf{1 b}}$ : Green construction procurement techniques are positively associated with sustainable transportation of materials

$\mathbf{H}_{\mathbf{1 c}}$ : Green Procurement policies are positively associated with sustainable packaging of shipping materials

$\mathbf{H}_{\mathbf{1 d}}$ : Green procurement policies are positively associated with sustainable transportation of materials

\section{Green Logistic Services With Sustainable Development Goals}

Logistic services management adheres to the green perspective of environmental protection that has been debated as an effective source for sustainable development. According to the United Nations, the basic root of sustainable goals is the improvement of social, environmental, and economic progress, and it tends to the development of future directions accordingly. The fundamental focus of improvement mentioned in this report (General Assembly of the United Nations) was the environmental stability and economic development of the SDGs. The motive of these SDGs is to attain environment-friendly procedures and technologies for innovating new strategies for the different manufacturing industries, which are somewhat similar to the new theory of green practices that is multidisciplinary and meets the modern requirements of the service industries. The sustainable goals that this study includes are SDG7, SDG8, and SDG9. These sustainable goals postulate as:

SDG7: Ensure access to affordable, reliable, sustainable, and modern energy for all

SDG8: Promote sustained, inclusive, and sustainable economic growth, full and productive employment, and decent work for all

SDG9: Build resilient infrastructure, promote inclusive and sustainable industrialization, and foster innovation

Many SDG achievements have been proposed in the past; certain achievements are brought into lines that support the acceptance and implementation of innovative technologies and practices that are the fundamental contributors in assisting organizations and overall industries in achieving greener supply chains (Centobelli et al., 2020). Furthermore, the changing dynamics of the construction industry, use of new technologies in devising the procurement policies and techniques that help environmental degradation, are offering a wide range of opportunities to organizations. Hence, based on the above literature, the following hypothesis has been formulated:

$\mathbf{H}_{\mathbf{2}}$ : Green logistic services management is positively associated with SDGs

These development goals cover all the aspects of economic sustainability. Logistics, transport services, and the shipping 
industry have been the highest contributors to environmental degradation (Centobelli et al., 2020; Karaman et al., 2020). Henceforth, there is an increasing trend of green technologies and practices, opening new doors of opportunities for the organizations currently operating in these logistic services management. The exploitation of these opportunities connecting the green organizational and production practices has led to more scalable, affordable, and measurable solutions that minimize the emission of hazardous gases and promote greener climate goals. The main hypothesis has been further broken down into two sub-hypotheses based on the sustainable packaging of shipping materials and sustainable transportation of materials.

$\mathbf{H}_{\mathbf{2 a}}$ : Sustainable packaging of shipping materials is positively associated with SDGs

$\mathbf{H}_{\mathbf{2 b}}$ : Sustainable transportation of materials is positively associated with SDGs

\section{Green Construction Procurement With Green Innovation Practices}

Green innovation is finding new ways for doing traditional activities that posit the least environmental harm or negative impacts on people. The possible harms commonly observed are the emission of gasses during extraction of raw materials and pollution during the products' working life and disposal. Procurement and green innovation are taking the products from "cradle to grave" to "cradle to cradle" via recyclable strategies. For the last 20 years, green requirements have been the center of attention of many researchers considering different perspectives of its implications in organizational performance; however, green procurement needs attention regarding its role in green innovation practices. Literature has mentioned the two main reasons for green innovation, i.e., whether it is responsive or proactive (Zailani et al., 2011; Bigliardi and Bertolini, 2012; Wong, 2013; Li et al., 2017; Melander, 2017; Abbas and Sağsan, 2019; Fernando et al., 2019). Responsive green innovation is the new feature in a product or process as a solution to a certain environmental problem. In contrast, proactive green innovation may be part of the organizational goal for cost-efficiency or profitability in the long run, in addition to green technology development for indulging in environment-friendly activities (Wong, 2012). Besides, the researchers Björklund and Forslund (2018) and Zailani et al. (2011) have a strong view that when procurement is done by green guidelines, which protect the environment, it leads to the adoption of new practices that contribute to the innovations of products and procedures that are aligned with the international guidelines that guard the environment against currently prevailing hazardous practices. To understand these roles, the following hypothesis has been devised:

$\mathbf{H}_{3}$ : Green procurement is positively associated with green innovation practices
Green innovation creates or adds value to a product and/or process by depicting the green perspective according to the industry, market, organization, or target population. Like conventional innovation, green innovation has also been broadly divided into two main categories, i.e., 1) green product innovation and 2) green process innovation (Zailani et al., 2011; Bigliardi and Bertolini, 2012; Wong, 2012; Wong, 2013; Abbas and Sağsan, 2019; Dantas et al., 2021). Green product innovation has been defined as adding a new feature to a product design or manufacturing or marketing in a new greener perspective that lags behind conventional innovations. Greenness has been described as a relative intangible concept that may evolve over the period considering the requirements and challenges arising according to the changing dynamics of the environment. Different treaties, regulating authorities and agencies, have established guidelines considering the changing standards for product development due to social, cultural, and ecological dynamics. A product is usually considered greener if it adds less harm to the environment at any stage of its life, from raw material to disposal (Song et al., 2015). When the techniques and policies are followed in procurement in any phase of the supply chain in the construction industry, it is supposed to be a determining factor in the innovation of products based on the green theory of innovation (Abbas and Sağsan, 2019; Tseng et al., 2021). Hence, when the techniques and policies adhering to the greener perspective in construction procurement are practiced, it has led to the innovation of green production.

On the other hand, green process innovation is the application of new and innovative ideas that are ecologically friendly, causing lesser harm than the present activities for the completion of products or delivering the services to consumers (Wong et al., 2016; Abbas and Sağsan, 2019). Furthermore, the innovation in the green process is usually characterized by the fulfillment of environmental criteria of maximum utilization of the natural resources, no or less ecological harm, following the sustainability issues in economic, social, and environmental aspects (Teng et al., 2018; Wang et al., 2018; Centobelli et al., 2020; Moşteanu et al., 2020; Tawfik Alqadami et al., 2020). However, it has also been mentioned that if the procurement techniques and policies have been incorporated considering the less harmful environmental perspectives, it will lead to the new ideas and implementation of such new processes and activities that meet the requirements of greener and sustainable economic activities (Wong, 2012; Wong et al., 2016). The products and processes with respect to innovation are interdependent and inseparable. Hence, the innovation in one of these factors contributes to the other, consequently, though a little. This helps in breaking down the $\mathrm{H}_{3}$ into four sub-hypotheses as

$\mathbf{H}_{3 \mathbf{a}}$ : Green construction procurement techniques are positively associated with green product innovation

$\mathbf{H}_{\mathbf{3 b}}$ : Green construction Procurement policies are positively associated with green product innovation

$\mathbf{H}_{3 \mathbf{c}}$ : Green construction procurement techniques are positively associated with green process innovation

$\mathbf{H}_{\mathbf{3 d}}$ : Green construction procurement policies are positively associated with green process innovation 


\section{Green Innovation Practices With Sustainable Development Goals}

Green practices are currently the hot topic for supply chain researchers, attaining sustainable goals, and improving global environmental concerns. Green innovation has been defined as finding new methods for practicing and experimenting the new products and processes that help environmental degradation (Fernando et al., 2019). New procedures and methods are constantly emerging, finding new practices, processes, and methods that make the environment the safest ground for all these human activities (Zailani et al., 2011; Björklund and Forslund, 2018). It is about inventing new processes, products, management structures, and environmentally friendly technologies and protecting them from hazards around with minimum use of resources and taking waste and pollution under control (Li et al., 2017; Abbas and Sağsan, 2019). Green innovation is related to both the products and processes, including the administrative tasks. New products and procedures are devised through these innovation strategies, and the old tasks could be done efficiently using new technologies. This leads to the formation of the following hypothesis:

$\mathbf{H}_{4}$ : Green innovation practices are positively associated with the attainment of SDGs

A wide range of green production guidelines is being followed to acquire sustainable development by efficient energy, resources management, advancement of smart technologies, novel policy developments, supply chains, and construction sectors (Giannetti et al., 2020). Based on the literature available on green production and other green practices, the need for such interdisciplinary research has been emphasized that addresses the effective ways of intervening green production with innovations that help in connecting with the attainment of SDGs (Huang et al., 2016; Li et al., 2017). According to Abbas and Sağsan (2019), the incorporation of green innovation of technology and procedures in organizational activities is positively contributing to environmental and economic sustainability.

Furthermore, policies that support innovative technologies and practices play a major role in helping the supply chain process of organization and logistics services in achieving the SDGs.

$\mathbf{H}_{4 \mathbf{a}}$ : Green product innovation is positively associated with the attainment of SDGs

$\mathbf{H}_{\mathbf{4 b}}$ : Green process innovation is positively associated with the attainment of SDGs

\section{Mediating Roles of Green Logistic Services and Green Innovation Practices}

Moreover, sustainable procurements and logistic services are needed more than ever since transportation and freight forwarding contribution toward the highest side of environmental degradation via the emission of harmful gasses (mainly Chlorofluorocarbons and Carbon dioxide) (Mohsin et al., 2021a; Mohsin et al., 2021b; Sarfraz et al., 2021). In the current scenarios of stress on green practices, the impact of green technologies and practices on business activities is exponentially growing and opening new opportunities for freight forwarders and the logistic services industry (Centobelli et al., 2020). Therefore, the logistic services and the innovative practices that follow the green guidelines can be the triggering factors for attaining the sustainable economic development goals that hold the construction procurement. When organizations invest in obtaining green industrial and business operations by stressing the development of green technology and innovations, it ultimately helps in economic sustainability. Therefore, the mediating role of green logistic services management and innovation practices has been proposed based on the literature reviewed. Considering the relationship of green logistic services and green innovation practices with green procurement and SDGs, the following hypotheses for the mediation have been devised.

$\mathbf{H}_{5}$ : Green logistic services mediate the relationship of green construction procurement and SDGs

$\mathbf{H}_{5 \mathbf{a}}$ : Sustainable packaging of shipping material mediates the relationship of green procurement techniques and SDGs

$\mathbf{H}_{\mathbf{5 b}}$ : Sustainable packaging of shipping material mediates the relationship of green procurement policies and SDGs

$\mathbf{H}_{5 \mathbf{c}}$ : Sustainable transportation of materials mediates the relationship of green procurement techniques and SDGs

$\mathbf{H}_{5 \mathbf{d}}$ : Sustainable transportation of materials mediates the relationship of green procurement policies and SDGs

Green innovation practices have been previously used as mediators for sustainable development (Abbas and Sağsan, 2019). Green innovations aim to introduce the new features in the products or activities necessary to convert the raw material obtained through procurement to the final product or service delivery aligned with the sustainable goals and less deterioration for the environment (Song et al., 2015). Such innovations usually aim to improve the quality aligned with sustainability, maximum utilization of natural resources, and minimization of their waste. Previously, the impact of green procurement has been checked in the manufacturing industry in China that found a significantly improved impact on their performance. The countries under infrastructural development need to contain the environmental hazards caused by the construction procurements and logistic services. Hence, on the basis of the literature support, the following hypotheses have been devised for the mediation:

$\mathbf{H}_{\mathbf{6}}$ : Green innovation practices mediate the relationship of green construction procurement and SDGs

$\mathbf{H}_{\mathbf{6 a}}$ : Green product innovation mediates the relationship of green procurement techniques and SDGs

$\mathbf{H}_{\mathbf{6}}$ : Green product innovation mediates the relationship of green procurement policies and SDGs

$\mathbf{H}_{\mathbf{6}}$ : Green process innovation mediates the relationship of green procurement techniques and SDGs 


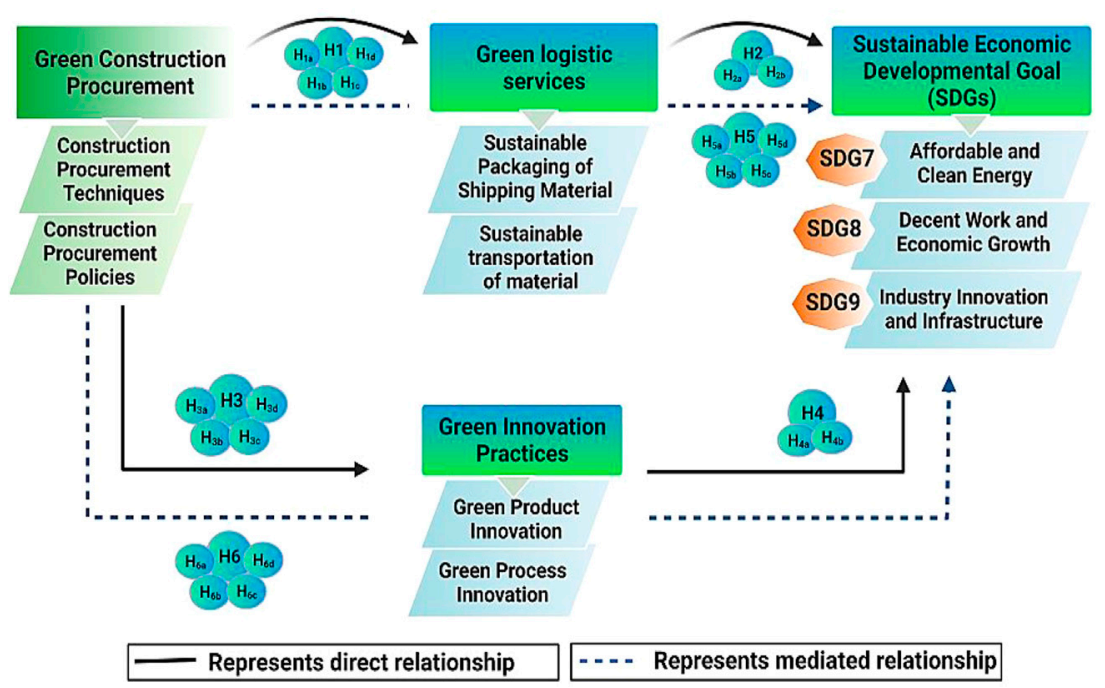

FIGURE 1 | Conceptual framework.

$\mathbf{H}_{\mathbf{6 d}}$ : Green process innovation mediates the relationship of green procurement policies and SDGs

\section{FRAMEWORK OF THE STUDY}

Based on the literature and hypothesis discussed earlier, the conceptual framework discussed later has been proposed in the study (see Figure 1).

The conceptual framework mentioned earlier operates on the green innovation theory that Hemmelskamp proposed in 1997, stating that there is a need for innovation that declines, lessens, or prevents the environmental deterioration, relates to the cleanup of wastes, addresses the problems of the environment, and contributes to the environmental sustainability and development through the ecological improvements (Bigliardi and Bertolini, 2012). Furthermore, the organizations and corporations involved in the construction procurement and logistics services are obliged to legal, economic, social, philanthropic, and ethical obligations for better surroundings and environment-friendly growth. The construction industry, being the major contributor to environmental hazards, proposes that if organizations work on the procurement mentioned earlier, sustainable energy and economic growth can be obtained through green logistic and innovation practices. Further validation of the proposed conceptual framework is presented in the forthcoming section of the results.

\section{RESEARCH METHODS}

According to one of the pioneer researchers, Woody (1924), good research should necessarily address the identification of a problem, form hypotheses, and suggest a clearer picture toward the solutions. Creswell et al. (2016) have termed research as a gathering of data and systematically analyzing it to get some patterns; however, some researchers have mentioned that research has to what, when, why, and how related questions to a certain problem, which are further investigated with a broader understanding of techniques and procedures for data analysis. This study follows a post-positivist approach of research methods because certain variables cause an effect on some other related variables. In this study, those effects will be measured. A quantitative study design has been selected with the deductive approach for reasoning with minimum bias and the use of the results from different perspectives. Generally, in quantitative studies, data are collected through surveys, questionnaires, closed-ended interviews, and certain rating scales. For the present study, self-administered surveys have been adopted for data collection. The population frame used in this study will be the managerial level staff of construction firms (project managers) and the civil engineers of the construction industry in China. The data in this study were collected with a simple random sampling technique of sample selection. Because the population is known for the registered companies in China stock exchanges, it is accessible for data collection. The sample size was obtained from the method of sample size selection described by Bhalerao and Kadam (2010), Adam (2020), and Archer et al., 2021. In addition, a sample size of 200 is considered as an adequate sample size. However, this study has taken a sample size of more than 300 to avoid any biases in the results. The unit of analysis in this study was individual (project managers of construction companies and civil engineers).

\section{Instrument Development}

The instrument used for data collection in this study was a questionnaire in which questions related to each respective variable are asked from the respondents through surveys. There is a total of four variables in this study. One is an independent variable, i.e., green procurement, which is further 
TABLE 1 | Demographic summary.

\begin{tabular}{lcc}
\hline Age & Frequency & Percentage \\
\hline$<20$ & 84 & 16.71 \\
$21-29$ & 225 & 44.73 \\
$30-39$ & 184 & 36.58 \\
$40-49$ & 10 & 1.98 \\
Sex & & \\
Male & 221 & 43.94 \\
Female & 282 & 56.06 \\
Profession & & \\
Project manager & 251 & 49.90 \\
Engineer & 252 & 50.10 \\
Education & & \\
Bachelor & 180 & 35.78 \\
Masters & 289 & 57.45 \\
Doctorate & 34 & 6.77 \\
Length of service & & \\
$<10$ & 304 & 60.44 \\
11-20 & 56 & 11.14 \\
$20>$ & 143 & 28.42 \\
\hline
\end{tabular}

Note: $N=503$

divided into green procurement techniques and green procurement policies; two mediating variables, i.e., green logistic services (which is subdivided into two sub-variables, i.e., sustainable packaging of shipping materials and sustainable transportation of material) and green innovation practices (which is further divided into two sub-variables, i.e., green product innovation and green process innovation); and one dependent variable of sustainable economic development goals (SGDs-SDG7, SDG8, and SDG9). The scales that were used for the variable green procurement were adapted from Wong et al. (2016), green logistic services from Ali et al. (2021), green innovation scale from Abbas and Sağsan (2019), and sustainable economic development goals from Dantas et al. (2021). As adapted from the previous studies, the current study will also follow the five-point Likert scale for documenting the respondents' responses ranging from "strongly disagree $=1$ " being the lowest degree of disagreement and "strongly agree $=5$ " being the highest degree of agreement. This study has used primary data because the data from the respondents are collected directly. In such cases, the primary data are either collected through interviews or questionnaire surveys; however, this study has used the survey method for the collection of data. To improve the quality of responses, the surveys were self-administered. The current study has used the latest version available of Smart-PLS for the data analysis of the study.

The demographic profile of the respondents has been analyzed with frequencies and percentages. Of the total respondents, $16.71 \%$ were below 20 years of age, whereas the highest percentage was between 21 and 29 years. Regarding sex, $43.94 \%$ were men, whereas the remaining $56.06 \%$ were women among the 503 total respondents. Furthermore, half of the respondents were project managers, and the other half were engineers, thus taking the proportionate respondents of the population frame. More detail is mentioned in Table $\mathbf{1 .}$

\section{DATA ANALYSIS}

Smart-PLS 3.3 was the software used for the data analysis obtained from the main study. The data of the main study were collected using the finalized questionnaire with deletion of two items, each from sustainable transportation of material and green process innovation, because both items showed the discriminant validities of less than 0.5 , which is the cutoff value (Sarstedt et al., 2019; Josephy and Marko, 2021). The data were tested in two stages: 1) measurement model algorithm and 2) structural model. Then, the data were tested for further validity and reliability with the results obtained from the measurement model algorithm. The measurement model algorithm can be seen in Figure 2.

The tests that the current study used for checking the discriminant validities were the heterotrait-monotrait (HTMT) ratio and the Fornell and Larcker criterion of validity (Franke and Sarstedt, 2019). The results obtained from these two tests are given in Tables $\mathbf{2}$ and $\mathbf{3}$. For the data to be valid, it is said that the values at the top of each should exceed and the rest of the values underneath (Franke and Sarstedt, 2019). Hence, this requirement has been met in this study, considering the highest value in each column lies at the top. The results of the Fornell and Larcker criterion can be seen in Table 2 .

To further validate the data, an HTMT ratio was obtained to find the convergent validity of the scales used in this study. For the HTMT ratio to be acceptable, these should not exceed 0.9 (Franke and Sarstedt, 2019). Table 4 gives the results for HTMT ratios, which are all well under the cutoff value reported in the literature, hence meeting the requirements of the convergent and discriminant validities for this study.

The data were further checked for reliability. This study used two types of reliabilities: Cronbach alpha (?) reliability and composite reliability. The results are given in Table 4 . Literature has believed that the higher the reliability of the scale, the better it is; however, the threshold for reliability has been set to be more than 0.7 (Hair et al., 2017; Sarstedt et al., 2019). All the values in this study for alpha reliabilities have been reported between 0.79 for sustainable transportation of materials and 0.93 for SDGs. Similar is the case for composite reliability; all the values are above 0.80 . Furthermore, the average variance extracted for a valid measurement scale should be more than 0.5 (Franke and Sarstedt, 2019), thus meeting the criteria of acceptable AVE.

The second stage of Smart-PLS gives the structural model algorithm that estimates $\mathrm{t}$-statistic significance values for the direct and indirect paths of the model to test the hypotheses formulated from the gaps in the literature review. Structural equation modeling is a multivariate analytical approach to measure the path effects (Sarstedt et al., 2019). The measurement model simultaneously measures the direct effects (direct relationships) and indirect effects (mediating) of independent variables on the dependent variables through a structural model algorithm obtained via consistent bootstrapping of 5,000 or more sub-sampling (Moqbel et al., 2020; Amora, 2021). The structural model of the study can be seen in Figure 3. 


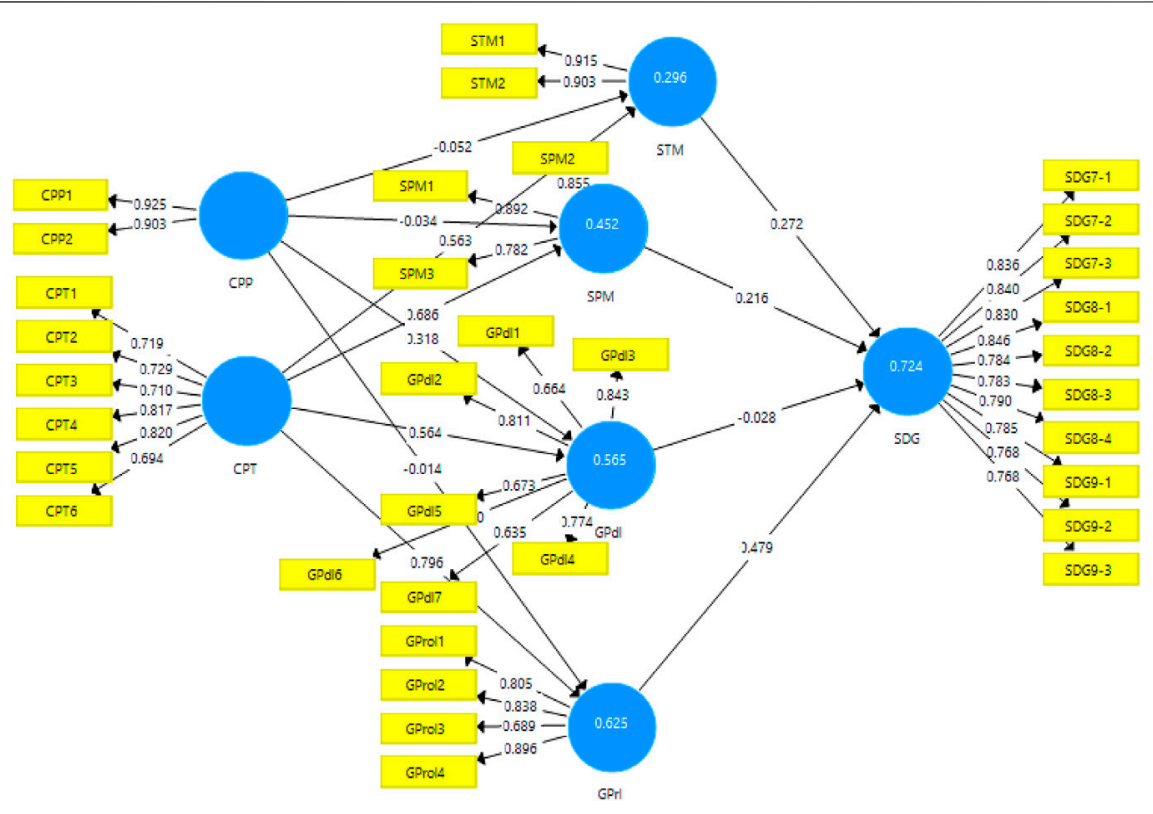

FIGURE 2 | Measurement model algorithm.

TABLE 2 | Fornell and Larcker criterion.

\begin{tabular}{llllllll} 
& CPP & CPT & GPdl & GPrl & SDG & SPM & STM \\
\hline CPP & 0.914 & & & & & & \\
CPT & 0.408 & $\mathbf{0 . 7 5 0}$ & & & & & \\
GPdl & 0.548 & 0.693 & $\mathbf{0 . 7 2 5}$ & & & & \\
GPrl & 0.311 & 0.790 & 0.575 & $\mathbf{0 . 8 1 0}$ & & & \\
SDG & 0.145 & 0.690 & 0.465 & 0.785 & $\mathbf{0 . 8 0 4}$ & & \\
SPM & 0.246 & 0.672 & 0.478 & 0.686 & 0.744 & $\mathbf{0 . 8 4 5}$ & \\
STM & 0.178 & 0.542 & 0.417 & 0.638 & 0.735 & 0.780 & $\mathbf{0 . 9 0 9}$
\end{tabular}

$N=503$; CPP, construction procurement policies; CPT, construction procurement techniques; GPdl, green product innovation; GPrl, green process innovation; SDG, sustainable economic development goals; SPM, sustainable packaging of material; STM, sustainable transportation of material.

Its shows the significance of each construct in particular table.

\begin{tabular}{|c|c|c|c|c|c|c|c|}
\hline & CPP & CPT & GPdl & GPrl & SDG & SPM & STM \\
\hline \multicolumn{8}{|l|}{ CPP } \\
\hline СРТ & 0.519 & & & & & & \\
\hline GPdl & 0.667 & 0.806 & & & & & \\
\hline GPrl & 0.386 & 0.864 & 0.682 & & & & \\
\hline SDG & 0.167 & 0.651 & 0.504 & 0.876 & & & \\
\hline SPM & 0.320 & 0.748 & 0.574 & 0.836 & 0.845 & & \\
\hline STM & 0.223 & 0.572 & 0.495 & 0.780 & 0.847 & 0.909 & \\
\hline
\end{tabular}

$N=503$; $C P P$, construction procurement policies; $C P T$, construction procurement techniques; GPdl, green product innovation; GPrl, green process innovation; SDG, sustainable economic development goals; SPM, sustainable packaging of material; STM, sustainable transportation of material.
The hypotheses were checked for their significance, with the results obtained at a $5 \%$ level of significance (Sekaran and Bougie, 2003; Sarstedt et al., 2019). The results obtained have been used for deciding the acceptance or rejection of the proposed hypotheses. Generally, the values obtained from the estimation of statistical tests of $t$-test, their respective $p$-values, R-squared values, and beta-values will be used. The study results can be seen in Tables $\mathbf{5}$ and $\mathbf{6}$ for the acceptance and rejection of hypotheses.

There were six hypotheses in the study, which were further divided depending on the constructs of each variable. The first hypothesis was about the association of green construction procurement to green logistic services $\mathrm{H}_{1}$ : Green procurement is positively associated with green logistic services. It was partially accepted, as its sub-hypotheses had been partially accepted, such as $\mathrm{H}_{1 \mathrm{a}}$ : Green procurement techniques are positively associated with sustainable packaging of shipping materials $t-$ statistic $=$ 22.615: $p$-value $=0.000$ as it is accepted, whereas $\mathrm{H}_{1 \mathrm{~b}}$ : Green procurement techniques are positively associated with sustainable transportation of materials, as it is also accepted at $t-$ statistic $=15.462: p-$ value $=0.000$. However, $\mathrm{H}_{1 \mathrm{c}}$ : Green procurement policies are positively associated with sustainable packaging of shipping materials $t-$ statistic $=0.863: p-$ value $=0.389, \quad$ and $\mathrm{H}_{1 \mathrm{~d}}: \quad$ Green procurement policies are positively associated with sustainable transportation of materials $t$-statistic $=1.165: p-$ value $=0.245$ is not accepted, showing significant levels of more than $5 \%$. For $\mathrm{H}_{2}$ : Green logistic services management is positively associated with SDGs that have been accepted, as its sub-hypotheses are also accepted, i.e., $\mathrm{H}_{2 \mathrm{a}}$ : Sustainable packaging of shipping materials is positively associated with SDGs $t-$ statistic $=4.772: p-$ value $=0.000 \quad \mathrm{H}_{2 \mathrm{~b}}: \quad$ Sustainable transportation of materials is positively associated with SDGs $t-$ statistic $=6.462: p-$ value $=0.000$. As long as $\mathrm{H}_{3}$ is 
TABLE 4 | Constructs reliabilities and AVE.

\begin{tabular}{|c|c|c|c|c|c|}
\hline Constructs & Code & FD & $a$ & CR & AVE \\
\hline \multirow[t]{3}{*}{ Construction procurement policies } & & & 0.805 & 0.911 & 0.836 \\
\hline & CPP1 & 0.925 & & & \\
\hline & CPP2 & 0.903 & & & \\
\hline \multirow[t]{7}{*}{ Construction procurement techniques } & & & 0.853 & 0.885 & 0.563 \\
\hline & CPT1 & 0.719 & & & \\
\hline & СРТ2 & 0.729 & & & \\
\hline & СРТЗ & 0.710 & & & \\
\hline & CPT4 & 0.817 & & & \\
\hline & CPT5 & 0.820 & & & \\
\hline & CPT6 & 0.694 & & & \\
\hline \multirow[t]{4}{*}{ Sustainable packaging of materials } & & & 0.798 & 0.882 & 0.713 \\
\hline & SPM1 & 0.892 & & & \\
\hline & SPM2 & 0.855 & & & \\
\hline & SPM3 & 0.782 & & & \\
\hline \multirow[t]{3}{*}{ Sustainable transportation of material } & & & 0.790 & 0.905 & 0.827 \\
\hline & STM1 & 0.915 & & & \\
\hline & STM2 & 0.903 & & & \\
\hline \multirow[t]{8}{*}{ Green product innovation } & & & 0.846 & 0.884 & 0.525 \\
\hline & GPdl1 & 0.664 & & & \\
\hline & GPdl2 & 0.811 & & & \\
\hline & GPdl3 & 0.843 & & & \\
\hline & GPdl4 & 0.774 & & & \\
\hline & GPdl5 & 0.673 & & & \\
\hline & GPdl6 & 0.640 & & & \\
\hline & GPdl7 & 0.635 & & & \\
\hline \multirow[t]{5}{*}{ Green process innovation } & & & 0.823 & 0.884 & 0.657 \\
\hline & GProl1 & 0.805 & & & \\
\hline & GProl2 & 0.838 & & & \\
\hline & GProl3 & 0.689 & & & \\
\hline & GProl4 & 0.896 & & & \\
\hline \multirow[t]{11}{*}{ Sustainable economic development goals } & & & 0.939 & 0.948 & 0.646 \\
\hline & SDG7-1 & 0.836 & & & \\
\hline & SDG7-2 & 0.840 & & & \\
\hline & SDG7-3 & 0.830 & & & \\
\hline & SDG8-1 & 0.846 & & & \\
\hline & SDG8-2 & 0.784 & & & \\
\hline & SDG8-3 & 0.783 & & & \\
\hline & SDG8-4 & 0.790 & & & \\
\hline & SDG9-1 & 0.785 & & & \\
\hline & SDG9-2 & 0.768 & & & \\
\hline & SDG9-3 & 0.768 & & & \\
\hline
\end{tabular}

Note: $N=503 ; F D$, factor loading; AVE, average variance extracted; $C R$, composite reliability.

Its shows the significance of each construct in particular table.

concerned, $\mathrm{H}_{3}$ : Green procurement is positively associated with green innovation practices; it is also accepted because all its subhypotheses are accepted, i.e., $\mathrm{H}_{3 \mathrm{a}}$ : Green procurement techniques are positively associated with green product innovation $t-$ statistic $=15.556: p-$ value $=0.000, \quad \mathrm{H}_{3 \mathrm{~b}}: \quad$ Green procurement techniques are positively associated with green process innovation $t$-statistic $=31.199: p-$ value $=0.000$, and $\mathrm{H}_{3 \mathrm{c}}$ : Green Procurement policies are positively associated green product innovation $t$-statistic $=7.217: p-$ value $=$ 0.000 except for $\mathrm{H}_{3 \mathrm{~d}}$ : Green procurement policies are positively associated with green process innovation $t$-statistic $=0.447: p-$ value $=0.655$. For the fourth hypothesis, $\mathrm{H}_{4}$ : Green innovation practices are positively associated with the attainment of SDGs; it is also partially accepted, as one of the two hypotheses are accepted, and others were rejected; $\mathrm{H}_{4 \mathrm{a}}$ : Green product innovation is positively associated with the attainment of SDGs $t-$ statistic $=$ $0.716: p-$ value $=0.474$ is rejected, whereas $\mathrm{H}_{4 \mathrm{~b}}$ : Green process innovation is positively associated with the attainment of SDGs $t-$ statistic $=9.081: p-$ value $=0.000$ is accepted. As for the mediations of the green logistic services, two of the four hypotheses were accepted. Details of each mediating hypothesis are as $\mathrm{H}_{5 \mathrm{a}}$ : Sustainable packaging of shipping material mediates the relationship of green procurement techniques and SDGs, $t-$ statistic $=4.532: p-$ value $=0.000$, is accepted at $5 \%$ level of significance. The second and third hypotheses of mediation, $\mathrm{H}_{5 \mathrm{~b}}$ : Sustainable packaging of shipping material mediates the relationship of green procurement policies and SDGs was accepted with $t-$ statistic $=5.637: p-$ value $=0.000$. However, $\mathrm{H}_{5 \mathrm{c}}$ : Sustainable transportation of materials mediates the relationship of green procurement techniques and SDGs with $t-$ statistic $=0.836: p-$ value $=0.404$ and $\mathrm{H}_{5 \mathrm{~d}}: \quad$ Sustainable 


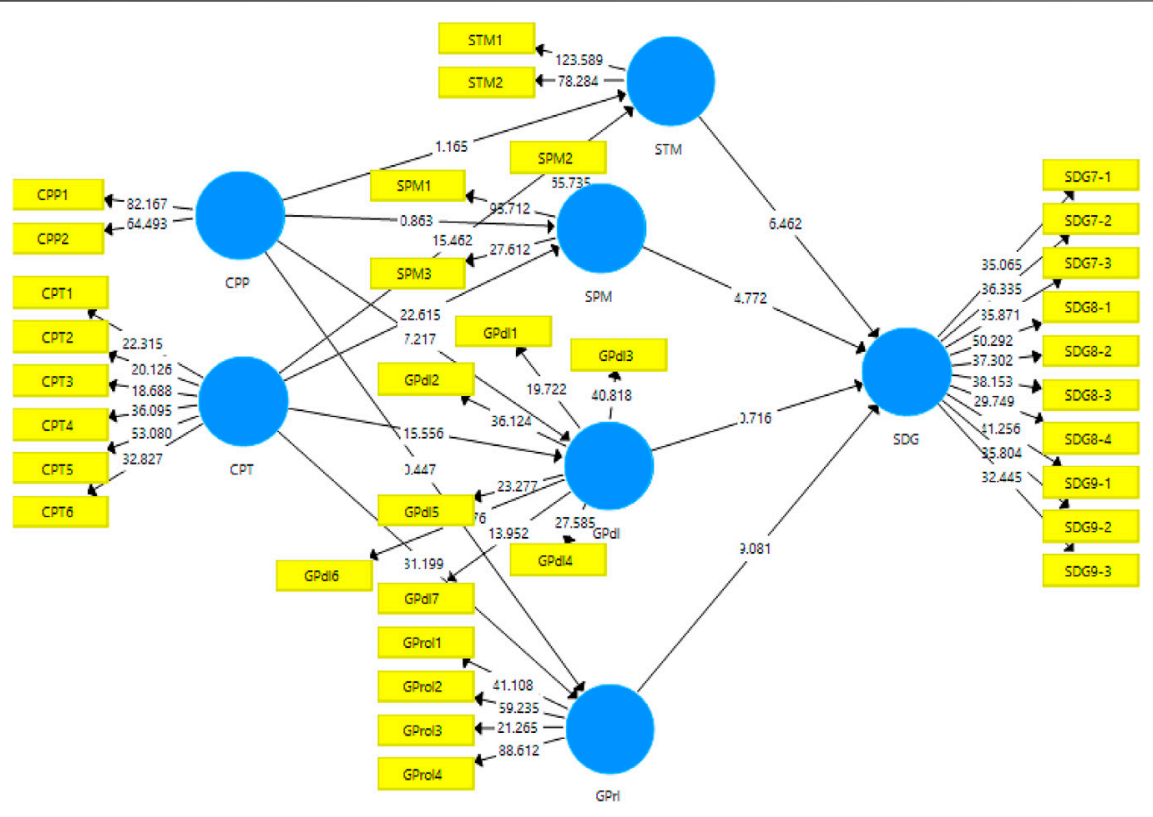

FIGURE 3 | Structural model.

TABLE 5 | Statistical results for structural model.

\begin{tabular}{|c|c|c|c|c|}
\hline Paths & $\mathbf{H}$ & 0 & $\mathbf{M}$ & SD \\
\hline $\mathrm{GP} \rightarrow \mathrm{GLS}$ & $\mathrm{H}_{1}$ & & & \\
\hline $\mathrm{CPT} \rightarrow \mathrm{SPM}$ & $\mathrm{H}_{1 \mathrm{a}}$ & 0.686 & 0.686 & 0.030 \\
\hline $\mathrm{CPT} \rightarrow \mathrm{STM}$ & $\mathrm{H}_{1 \mathrm{~b}}$ & 0.563 & 0.565 & 0.036 \\
\hline $\mathrm{CPP} \rightarrow \mathrm{SPM}$ & $\mathrm{H}_{1 \mathrm{c}}$ & -0.034 & -0.034 & 0.040 \\
\hline $\mathrm{CPP} \rightarrow \mathrm{STM}$ & $\mathrm{H}_{1 \mathrm{~d}}$ & -0.052 & -0.052 & 0.044 \\
\hline GLS $\rightarrow$ SDG & $\mathrm{H}_{2}$ & & & \\
\hline $\mathrm{SPM} \rightarrow \mathrm{SDG}$ & $\mathrm{H}_{2 \mathrm{a}}$ & 0.216 & 0.215 & 0.045 \\
\hline $\mathrm{STM} \rightarrow \mathrm{SDG}$ & $\mathrm{H}_{2 \mathrm{~b}}$ & 0.272 & 0.272 & 0.042 \\
\hline $\mathrm{GP} \rightarrow \mathrm{GIP}$ & $\mathrm{H}_{3}$ & & & \\
\hline $\mathrm{CPT} \rightarrow \mathrm{GPdl}$ & $\mathrm{H}_{3 \mathrm{a}}$ & 0.564 & 0.566 & 0.036 \\
\hline $\mathrm{CPT} \rightarrow \mathrm{GPrl}$ & $\mathrm{H}_{3 \mathrm{~b}}$ & 0.796 & 0.796 & 0.026 \\
\hline $\mathrm{CPP} \rightarrow \mathrm{GPdl}$ & $\mathrm{H}_{3 \mathrm{c}}$ & 0.318 & 0.317 & 0.044 \\
\hline $\mathrm{CPP} \rightarrow \mathrm{GPrl}$ & $\mathrm{H}_{3 \mathrm{~d}}$ & -0.014 & -0.013 & 0.032 \\
\hline $\mathrm{GIP} \rightarrow \mathrm{SDG}$ & $\mathrm{H}_{4}$ & & & \\
\hline $\mathrm{GPdl} \rightarrow \mathrm{SDG}$ & $\mathrm{H}_{4 a}$ & -0.028 & -0.027 & 0.039 \\
\hline $\mathrm{GPrl} \rightarrow \mathrm{SDG}$ & $\mathrm{H}_{4 \mathrm{~b}}$ & 0.479 & 0.481 & 0.053 \\
\hline $\mathrm{GP} \rightarrow \mathrm{GLS} \rightarrow \mathrm{SDG}$ & $\mathrm{H}_{5}$ & & & \\
\hline $\mathrm{CPT} \rightarrow \mathrm{SPM} \rightarrow \mathrm{SDG}$ & $\mathrm{H}_{5 \mathrm{a}}$ & 0.148 & 0.148 & 0.033 \\
\hline $\mathrm{CPT} \rightarrow \mathrm{STM} \rightarrow \mathrm{SDG}$ & $\mathrm{H}_{5 b}$ & 0.153 & 0.154 & 0.027 \\
\hline $\mathrm{CPP} \rightarrow \mathrm{SPM} \rightarrow \mathrm{SDG}$ & $\mathrm{H}_{5 \mathrm{c}}$ & -0.007 & -0.007 & 0.009 \\
\hline \multicolumn{5}{|l|}{$\mathrm{CPP} \rightarrow \mathrm{STM} \rightarrow \mathrm{SDG}$} \\
\hline $\mathrm{GP} \rightarrow \mathrm{GIP} \rightarrow \mathrm{SDG}$ & $\mathrm{H}_{5 \mathrm{~d}}$ & -0.014 & -0.015 & 0.013 \\
\hline & $\mathrm{H}_{6}$ & & & \\
\hline $\mathrm{CPT} \rightarrow \mathrm{GPdl} \rightarrow \mathrm{SDG}$ & $\mathrm{H}_{6 \mathrm{a}}$ & -0.016 & -0.015 & 0.022 \\
\hline $\mathrm{CPT} \rightarrow \mathrm{GPrl} \rightarrow \mathrm{SDG}$ & $\mathrm{H}_{6 b}$ & 0.381 & 0.384 & 0.050 \\
\hline $\mathrm{CPP} \rightarrow \mathrm{GPdl} \rightarrow \mathrm{SDG}$ & $\mathrm{H}_{6 c}$ & -0.009 & -0.009 & 0.013 \\
\hline $\mathrm{CPP} \rightarrow \mathrm{GPrl} \rightarrow \mathrm{SDG}$ & $\mathrm{H}_{6 \mathrm{~d}}$ & -0.007 & -0.006 & 0.015 \\
\hline
\end{tabular}

Note: $N=503 ; H$, hypotheses; $O$, original sample; $M$, sample mean; $S D$, standard deviation; GP, green procurement; GLS, green logistic services; CPP, construction procurement policies; CPT, construction procurement techniques; GIP, green innovation practices, GPdl, green product innovation; GPrl, green process innovation; SDG, sustainable economic development goals; SPM, sustainable packaging of material; STM, sustainable transportation of material. transportation of materials mediates the relationship of green procurement policies and SDGs with $t-$ statistic $=1.102: p-$ value $=0.271$ are rejected. As for the mediation of green innovation practices, one of four hypotheses is accepted. The hypothesis $\mathrm{H}_{6 \mathrm{a}}$ : Green product innovation mediates the relationship of green procurement techniques and SDGs $t-$ statistic $=0.712: p-$ value $=0.477 ; \quad \mathrm{H}_{6 \mathrm{~b}}:$ Green product innovation mediates the relationship of green procurement policies and SDGs is accepted with $t-$ statistic $=7.687: p-$ value $=0.000$, whereas others are rejected based on their respective t-values. $\mathrm{H}_{6 c}$ : Green process innovation mediates the relationship of green procurement techniques and SDGs $t$-statistic $=0.692: p-$ value $=0.483$ and $\mathrm{H}_{6 \mathrm{~d}}$ : Green process innovation mediates the relationship of green procurement policies and SDGs $t-$ statistic $=0.660: p-$ value $=0.440$.

\section{DISCUSSIONS}

The current study is based on six hypotheses measuring the role of construction procurement in achieving SDGs with the mediating roles of green logistics services and green innovation practices. Each hypothesis is divided into further sub-hypotheses based on their subsequent constructs. In this rapidly growing infrastructure era, green construction practices offer wide opportunities to explore the environmental benefits. First of all, the demographic information of the respondents is analyzed using frequencies and percentages. This study used two types of reliabilities: the Cronbach alpha (?) reliability and the composite reliability. The results are given in Table 4 . Literature has witnessed that the higher the reliability of the scale, the better it is; however, the threshold for reliability has been set to be more 
TABLE 6 | Hypotheses result from a structural model.

\begin{tabular}{|c|c|c|c|c|c|c|}
\hline Paths & $\mathbf{H}$ & f-square & Adjusted $\mathbf{R}^{2}$ & T-stats & $p$-Value & Results \\
\hline $\mathrm{GP} \rightarrow \mathrm{GLS}$ & $\mathrm{H}_{1}$ & & & & & Partially Accepted \\
\hline $\mathrm{CPT} \rightarrow \mathrm{SPM}$ & $\mathrm{H}_{1 \mathrm{a}}$ & 0.716 & 0.452 & 22.615 & $0.000^{\star \star \star}$ & Accepted \\
\hline $\mathrm{CPT} \rightarrow \mathrm{STM}$ & $\mathrm{H}_{1 \mathrm{~b}}$ & 0.375 & 0.296 & 15.462 & $0.000^{\star \star \star}$ & Accepted \\
\hline $\mathrm{CPP} \rightarrow \mathrm{SPM}$ & $\mathrm{H}_{1 \mathrm{c}}$ & 0.002 & & 0.863 & 0.389 & Rejected \\
\hline $\mathrm{CPP} \rightarrow \mathrm{STM}$ & $\mathrm{H}_{1 \mathrm{~d}}$ & 0.003 & & 1.165 & 0.245 & Rejected \\
\hline $\mathrm{GLS} \rightarrow \mathrm{SDG}$ & $\mathrm{H}_{2}$ & & & & & Accepted \\
\hline $\mathrm{SPM} \rightarrow \mathrm{SDG}$ & $\mathrm{H}_{2 \mathrm{a}}$ & 0.055 & 0.724 & 4.772 & $0.000^{\star \star \star}$ & Accepted \\
\hline $\mathrm{STM} \rightarrow \mathrm{SDG}$ & $\mathrm{H}_{2 \mathrm{~b}}$ & 0.100 & & 6.462 & $0.000^{\star \star \star}$ & Accepted \\
\hline $\mathrm{GP} \rightarrow \mathrm{GIP}$ & $\mathrm{H}_{3}$ & & & & & Accepted \\
\hline $\mathrm{CPT} \rightarrow \mathrm{GPdl}$ & $\mathrm{H}_{3 a}$ & 0.609 & 0.565 & 15.556 & $0.000^{\star \star \star}$ & Accepted \\
\hline $\mathrm{CPT} \rightarrow \mathrm{GPrl}$ & $\mathrm{H}_{3 b}$ & 1.409 & 0.625 & 31.199 & $0.000^{\star \star \star}$ & Accepted \\
\hline $\mathrm{CPP} \rightarrow \mathrm{GPdl}$ & $\mathrm{H}_{3 \mathrm{c}}$ & 0.194 & & 7.217 & $0.000^{\star \star \star}$ & Accepted \\
\hline $\mathrm{CPP} \rightarrow \mathrm{GPrl}$ & $\mathrm{H}_{3 \mathrm{~d}}$ & 0.000 & & 0.447 & 0.655 & Rejected \\
\hline $\mathrm{GIP} \rightarrow \mathrm{SDG}$ & $\mathrm{H}_{4}$ & & & & & Partially Accepted \\
\hline GPdl $\rightarrow$ SDG & $\mathrm{H}_{4 a}$ & 0.002 & & 0.716 & 0.474 & Rejected \\
\hline GPrl $\rightarrow$ SDG & $\mathrm{H}_{4 b}$ & 0.358 & & 9.081 & $0.000^{\star \star \star}$ & Accepted \\
\hline $\mathrm{CPT} \rightarrow \mathrm{SPM} \rightarrow \mathrm{SDG}$ & $\mathrm{H}_{5 \mathrm{a}}$ & & & 4.532 & $0.000^{\star \star \star}$ & Accepted \\
\hline $\mathrm{CPT} \rightarrow \mathrm{STM} \rightarrow \mathrm{SDG}$ & $\mathrm{H}_{5 b}$ & & & 5.637 & $0.000^{\star \star \star}$ & Accepted \\
\hline $\mathrm{CPP} \rightarrow \mathrm{SPM} \rightarrow \mathrm{SDG}$ & $\mathrm{H}_{5 \mathrm{c}}$ & & & 0.836 & 0.404 & Rejected \\
\hline $\mathrm{CPP} \rightarrow \mathrm{STM} \rightarrow \mathrm{SDG}$ & $\mathrm{H}_{5 \mathrm{~d}}$ & & & 1.102 & 0.271 & Rejected \\
\hline $\mathrm{CPT} \rightarrow \mathrm{GPdl} \rightarrow \mathrm{SDG}$ & $\mathrm{H}_{6 \mathrm{a}}$ & & & 0.712 & 0.477 & Rejected \\
\hline $\mathrm{CPT} \rightarrow \mathrm{GPrl} \rightarrow \mathrm{SDG}$ & $\mathrm{H}_{6 b}$ & & & 7.687 & $0.000^{\star \star \star}$ & Accepted \\
\hline $\mathrm{CPP} \rightarrow \mathrm{GPdl} \rightarrow \mathrm{SDG}$ & $\mathrm{H}_{6 c}$ & & & 0.692 & 0.489 & Rejected \\
\hline $\mathrm{CPP} \rightarrow \mathrm{GPrl} \rightarrow \mathrm{SDG}$ & $\mathrm{H}_{6 \mathrm{~d}}$ & & & 0.440 & 0.660 & Rejected \\
\hline
\end{tabular}

Note: $N=503 ; \mathrm{H}$, hypotheses; O, original sample; $M$, sample mean; $S D$, standard deviation; ${ }^{* * *} \mathrm{p}<0.0005,{ }^{* *} \mathrm{p}<0.005$, ${ }^{*} \mathrm{p}<0.05$; GP, green procurement; GLS, green logistic services; CPP, construction procurement policies; CPT, construction procurement techniques; GIP, green innovation practices; GPdl, green product innovation; GPrl, green process innovation; SDG, sustainable economic development goals; SPM, sustainable packaging of material; STM, sustainable transportation of material.

Its shows the significance of each construct in particular table.

than 0.7 (Hair et al., 2017; Sarstedt et al., 2019; Hair and Sarstedt, 2021). All the values in this study for alpha (?) reliabilities have been reported between 0.79 for sustainable transportation of materials and 0.93 for sustainable development goals. Similar is the case for composite reliability; all the values are above 0.8 .

Furthermore, the average variance extracted for a valid measurement scale should be more than 0.5 (Franke and Sarstedt, 2019), thus meeting the criteria of acceptable AVE. The second stage of Smart-PLS gives the structural model that estimates t-statistic significance values for the direct and indirect paths of the model to test the hypotheses formulated from the gaps in the literature review. The current study's tests were used for checking the discriminant validities, HTMT ratio and the Fronell and Larcker criterion of validity (Franke and Sarstedt, 2019). Hence, this requirement has been met in this study, considering the highest value in each column lies at the top. Structural equation modeling is a multivariate analytical approach to measure the path effects (Sarstedt et al., 2019). The measurement model simultaneously measures the direct effects (direct relationships) and indirect effects (mediating) of independent variables on the dependent variables through a structural model algorithm obtained via consistent bootstrapping of 5,000 or more sub-sampling (Moqbel et al., 2020; Amora, 2021). The first hypothesis, $\mathrm{H}_{1}$, about the association of green construction procurement with green logistic services, was partially accepted because a change in policies does not contribute to green logistic practices unless construction procurement techniques in accordance with green practices altogether are not in practice, which changes the logistic services approach that is less hazardous to the environment (Centobelli et al., 2020). $\mathrm{H}_{2}$, regarding the positive role of green logistic services in achieving SDGs was accepted as environment-friendly logistic services, has been found previously as the key factor for achieving sustainable goals (Tawfik Alqadami et al., 2020; Dantas et al., 2021).

Regarding $\mathrm{H}_{3}$, construction procurement aligned with the green environmental guidelines has been found to be a major determinant in green innovation practices. This is because a change in the construction procurement regarding policies and techniques leads to the innovation of new practices that are greener than before and contribute to the positive impact on the environment (Zailani et al., 2011; Wong, 2012; Björklund and Forslund, 2018). In $\mathrm{H}_{4}$, the results also showed the partial acceptance of the hypothesis. In this study, the innovation of green processes was found to be a significant triggering contributor to the attainment of SDGs than the product innovation, which is so much in accordance with the previous studies (Wong, 2012; Abbas and Sağsan, 2019). This is because when the innovative practices in the organizations are done considering lest of environmental degradation, this leads to the achievement of SDGs given by the United Nations.

As for the mediation of green logistic services and green innovation practices, these hypotheses $\left(\mathrm{H}_{5}, \mathrm{H}_{6}\right)$ were partially accepted (see Table 6). The relationship of construction procurement techniques and SGDs was significantly mediated by green logistic services management (i.e., sustainable packaging 
of shipping materials and sustainable transportation of materials) because the logistic services are a fundamental component of supply chains in the construction industry; however, the innovation practices are not mandatory for the attainment of successful project performance. The context-based analysis has indicated the insignificant mediation of green product innovation among the construction procurement and SDGs because the supply chain is a service based in the construction industry, hence, not signifying the mediation of product innovation. Among the green product and green process innovations, green process innovation has been found to be a catalyst to enhance the role of construction procurement in the SDGs (Abbas and Sağsan, 2019). The current model focuses on the service industry of construction; hence, process innovation has been found to be a significant mediator for this particular relationship.

\section{CONCLUSION AND MANAGERIAL IMPLICATIONS}

Based on the green innovation theory, a conceptual framework was devised to understand the underlying mechanism of green construction procurement and its relationship with green logistic services, innovation practices, and their role in attaining SDGs sustainability. The findings of the current study show that green procurement partially contributes to the green logistic services, which determines the attainment of SDGs. On the other hand, green procurement has significantly predicted green innovation practices, which partially determine its role in economic sustainability. As long as the moderating roles of green logistic services management and green innovation practices are concerned, they have partially mediated the relationship of green construction procurement and SDGs. Moreover, this study has highlighted the importance of green procurement in achieving SDGs and the importance of green logistic services management and green innovation practices throughout the supply chain in building infrastructure. Organizations should be promoted for strategizing their procurement and logistic services in a greener way for substantial contribution to the environmental up-gradation and economic developments at the mass level. These factors are suggestive to see the broader beneficial outcomes for indulging in green practices through construction supply chains. The results obtained can be objectively proposed to recommend effective and efficient adoption of green procurement in the construction industry. Construction organizations have to be aware of the green

\section{REFERENCES}

Abbas, J., and Sağsan, M. (2019). Impact of Knowledge Management Practices on green Innovation and Corporate Sustainable Development: A Structural Analysis. J. Clean. Prod. 229, 611-620. doi:10.1016/j.jclepro.2019.05.024

Adam, A. M. (2020). Sample Size Determination in Survey Research. Jsrr, 90-97. doi:10.9734/jsrr/2020/v26i530263 aspect in the procurement of raw materials and intriguing green logistic services management. These green product and process innovations are considered a big determinant of sustainable economic development, although it is a timeconsuming process; however, it can improve organizational efficiency in the short term by upgrading the procurement, logistic, and innovation practices. Currently, practicing green construction procurement, logistic services, and innovation is challenging, as "turning into green" often differs in its requirements. Therefore, construction companies should indulge in such green practices that tend to balance all stakeholders' benefits to get aligned with their policies and agreements.

\section{LIMITATION OF STUDY}

Certain limitations of the study have been embedded in the current study, which can be covered in future studies for getting more generalized and applicable results. First of all, it is a cross-sectional study, which can be validated further by taking data from another point of time and comparing the performance and achievement of organizations in achieving green practices in supply chains in the construction industry. Secondly, more variables related to construction procurement and logistic services can be incorporated in the theoretical framework for getting more factual results, which can suggest further modifications in the practical implications. The current study is conducted in China; it should be replicated in other parts of Europe and the Gulf to validate the generalizability of the results.

\section{DATA AVAILABILITY STATEMENT}

The original contributions presented in the study are included in the article/Supplementary Material; further inquiries can be directed to the corresponding author.

\section{AUTHOR CONTRIBUTIONS}

TS and YC conceived and designed the concept literature review and data collection and wrote the paper. AR and $\mathrm{ZH}$ helped to provide technical support and contributed to analysis tools. AN has reviewed the work to improve the outcomes. All authors have read and agreed to the published version of the article.

Ali, A. H., Melkonyan, A., Noche, B., and Gruchmann, T. (2021). Developing a Sustainable Logistics Service Quality Scale for Logistics Service Providers in Egypt. Logistics 5, 21. doi:10.3390/logistics5020021

Amora, J. T. (2021). Convergent Validity Assessment in PLS-SEM : A LoadingsDriven Approach. Data Anal. Perspect. J. 2, 1-6.

Archer, L., Snell, K. I. E., Ensor, J., Hudda, M. T., Collins, G. S., and Riley, R. D. (2021). Minimum Sample Size for External Validation of a Clinical Prediction Model with a Continuous Outcome. Stat. Med. 40, 133-146. doi:10.1002/sim.8766 
Awan, U., Sroufe, R., and Kraslawski, A. (2019). Creativity Enables Sustainable Development: Supplier Engagement as a Boundary Condition for the Positive Effect on Green Innovation. J. Clean. Prod. 226, 172-185. doi:10.1016/j.jclepro. 2019.03.308

Bhalerao, S., and Kadam, P. (2010). Sample Size Calculation. Int. J. Ayurveda Res. 1, 55. doi:10.4103/0974-7788.59946

Bigliardi, B., and Bertolini, M. (2012). Green Innovation Management: Theory and Practice. Euro Jrnl of Inn Mnagmnt 15. doi:10.1108/EJIM.2012.22015DAA.001

Björklund, M., and Forslund, H. (2018). A Framework for Classifying Sustainable Logistics Innovations. Logist. Res. 11, 1-12. doi:10.23773/2018_1

Bohari, A. A. M., Skitmore, M., Xia, B., and Teo, M. (2017). Green Oriented Procurement for Building Projects: Preliminary Findings from Malaysia. J. Clean. Prod. 148, 690-700. doi:10.1016/j.jclepro.2017.01.141

Centobelli, P., Cerchione, R., and Esposito, E. (2020). Pursuing Supply Chain Sustainable Development Goals through the Adoption of green Practices and Enabling Technologies: A Cross-Country Analysis of LSPs. Technol. Forecast. Soc. Change 153, 119920. doi:10.1016/j.techfore.2020. 119920

Creswell, J. W., Hanson, W. E., Plano, V. L. C., and Morales, A. (2016). Qualitative Research Designs: Selection and Implementation. Couns. Psychol. 35. doi:10. 1177/0011000006287390

Croce, A. I., Musolino, G., Rindone, C., and Vitetta, A. (2019). Sustainable Mobility and Energy Resources: A Quantitative Assessment of Transport Services with Electrical Vehicles. Renew. Sust. Energ. Rev. 113, 109236. doi:10.1016/J.RSER. 2019.06.043

Dantas, T. E. T., de-Souza, E. D., Destro, I. R., Hammes, G., Rodriguez, C. M. T., and Soares, S. R. (2021). How the Combination of Circular Economy and Industry 4.0 Can Contribute towards Achieving the Sustainable Development Goals. Sustainable Prod. Consumption 26, 213-227. doi:10.1016/j.spc.2020. 10.005

Fernando, Y., Chiappetta Jabbour, C. J., and Wah, W.-X. (2019). Pursuing green Growth in Technology Firms through the Connections between Environmental Innovation and Sustainable Business Performance: Does Service Capability Matter? Resour. Conservation Recycling 141, 8-20. doi:10.1016/j.resconrec. 2018.09.031

Franke, G., and Sarstedt, M. (2019). Heuristics versus Statistics in Discriminant Validity Testing: a Comparison of Four Procedures. Intr 29, 430-447. doi:10. 1108/IntR-12-2017-0515

Giannetti, B. F., Agostinho, F., Eras, J. J. C., Yang, Z., and Almeida, C. M. V. B. (2020). Cleaner Production for Achieving the Sustainable Development Goals. J. Clean. Prod. 271, 122127. doi:10.1016/j.jclepro.2020.122127

Hair, J. F. J., Hult, G. T. M., Ringle, C. M., and Sarstedt, M. (2017). A primer on partial least squares structural equation modeling (PLS-SEM).

Huang, X.-x., Hu, Z.-p., Liu, C.-s., Yu, D.-j., and Yu, L.-f. (2016). The Relationships between Regulatory and Customer Pressure, green Organizational Responses, and green Innovation Performance. J. Clean. Prod. 112, 3423-3433. doi:10. 1016/j.jclepro.2015.10.106

Huo, C., Ahmed Dar, A., Nawaz, A., Hameed, J., albashar, G., Pan, B., et al. (2021). Groundwater Contamination with the Threat of COVID-19: Insights into CSR Theory of Carroll's Pyramid. J. King Saud Univ. - Sci. 33, 101295. doi:10.1016/j. jksus.2020.101295

Josephy, Hair., and Marko, S. (2021). Data, Measurement, and Causal Inferences in Machine Learning: Opportunities and Challenges for Marketing. J. Mark. Theor. Pract. 29.

Kam-Sing Wong, S. (2012). The Influence of green Product Competitiveness on the success of green Product Innovation. Euro Jrnl of Inn Mnagmnt 15, 468-490. doi:10.1108/14601061211272385

Karaman, A. S., Kilic, M., and Uyar, A. (2020). Green Logistics Performance and Sustainability Reporting Practices of the Logistics Sector: The Moderating Effect of Corporate Governance. J. Clean. Prod. 258, 120718. doi:10.1016/j.jclepro.2020.120718

Lăzăroiu, G., Ionescu, L., Uță, C., Hurloiu, I., Andronie, M., and Dijmărescu, I. (2020). Environmentally Responsible Behavior and Sustainability Policy Adoption in Green Public Procurement. Sustainability 12, 2110. doi:10. 3390/su12052110

Li, D., Zheng, M., Cao, C., Chen, X., Ren, S., and Huang, M. (2017). The Impact of Legitimacy Pressure and Corporate Profitability on green Innovation: Evidence from China Top 100. J. Clean. Prod. 141, 41-49. doi:10.1016/J.JCLEPRO.2016. 08.123
Melander, L. (2017). Achieving Sustainable Development by Collaborating in Green Product Innovation. Bus. Strat. Env. 26, 1095-1109. doi:10.1002/bse. 1970

Mohsin, M., Naseem, S., Sarfraz, M., Ivascu, L., and Albasher, G. (2021a). COVID19 and Greenhouse Gas Emission Mitigation: Modeling the Impact on Environmental Sustainability and Policies. Front. Environ. Sci. doi:10.3389/ fenvs.2021.764294

Mohsin, M., Zhu, Q., Naseem, S., Sarfraz, M., and Ivascu, L. (2021b). Mining Industry Impact on Environmental Sustainability, Economic Growth, Social Interaction, and Public Health: An Application of Semi-quantitative Mathematical Approach. Processes 9, 972. doi:10.3390/pr9060972

Moqbel, M., Guduru, R., and Harun, A. (2020). Testing Mediation via Indirect Effects in PLS-SEM : A Social Networking Site Illustration. Data Anal. Perspect. J. 1, 1-6.

Moşteanu, N. R., Faccia, A., and Cavaliere, L. P. L. (2020). Digitalization and Green Economy - Changes of Business Perspectives. ACM Int. Conf. Proceeding Ser., 108-112. doi:10.1145/3416921.3416929

Naseem, S., Fu, G. L., Mohsin, M., Rehman, M. Z.-u., and Baig, S. A. (2020). SemiQuantitative Environmental Impact Assessment of Khewra Salt Mine of Pakistan: an Application of Mathematical Approach of Environmental Sustainability. Mining, Metall. Exploration 37, 1185-1196. doi:10.1007/ s42461-020-00214-9

Naseem, S., Mohsin, M., Zia-Ur-Rehman, M., Baig, S. A., and Sarfraz, M. (2021). The Influence of Energy Consumption and Economic Growth on Environmental Degradation in BRICS Countries: an Application of the ARDL Model and Decoupling index. Environ. Sci. Pollut. Res., 1-14. doi:10. 1007/s11356-021-16533-3

Nawaz, A., Raheel Shah, S. A., Su, X., Dar, A. A., Qin, Z., and Gadah Albasher, Gadah. (2021). Analytical Strategies to Sense Water Stress Level: An Analysis of Ground Water Fluctuations Sensing SDGs under Pandemic Scenario. Chemosphere, 132924. doi:10.1016/j.chemosphere.2021.132924

Nawaz, A., Waqar, A., Shah, S., Sajid, M., and Khalid, M. (2019). An Innovative Framework for Risk Management in Construction Projects in Developing Countries: Evidence from Pakistan. Risks 7, 24. doi:10.3390/risks7010024

Porter, M. E., and Linde, C. v. d. (1995). Toward a New Conception of the Environment-Competitiveness Relationship. J. Econ. Perspect. 9, 97-118. doi:10.1257/JEP.9.4.97

Sarfraz, M., Mohsin, M., Naseem, S., and Kumar, A. (2021). Modeling the Relationship between Carbon Emissions and Environmental Sustainability during COVID-19: A New Evidence from Asymmetric ARDL Cointegration Approach. Environ. Dev. Sustain. 1-19. doi:10.1007/ s10668-021-01324-0

Sarstedt, M., Hair, J. F., Cheah, J.-H., Becker, J.-M., and Ringle, C. M. (2019). How to Specify, Estimate, and Validate Higher-Order Constructs in PLS-SEM. Australas. Marketing J. 27, 197-211. doi:10.1016/j.ausmj.2019.05.003

Sekaran, U., and Bougie, R. (20032003). Research Methods for Business: A Skill-Building Approach. 4th Edition. New York: John Wiley \& SonsJohn Wiley \& Sons.

Song, H., Yu, K., and Zhang, S. (2017). Green Procurement, Stakeholder Satisfaction and Operational Performance. Ijlm 28, 1054-1077. doi:10.1108/ IJLM-12-2015-0234

Tan, B. Q., Wang, F., Liu, J., Kang, K., and Costa, F. (2020). A Blockchain-Based Framework for Green Logistics in Supply Chains. Sustainability 12, 4656. doi:10.3390/su12114656

Tawfik Alqadami, A., Abdullah Zawawi, N. A. W., Rahmawati, Y., Alaloul, W., and Faisal Alshalif, A. (2020). Key Success Factors of Implementing Green Procurement in Public Construction Projects in Malaysia. IOP Conf. Ser. Earth Environ. Sci. 498, 012098. doi:10.1088/1755-1315/498/1/012098

Teng, J., Mu, X., Wang, W., Xu, C., and Liu, W. (2019). Strategies for Sustainable Development of Green Buildings. Sust. Cities Soc. 44, 215-226. doi:10.1016/j. scs.2018.09.038

Tseng, M.-L., Tran, T. P. T., Ha, H. M., Bui, T.-D., and Lim, M. K. (2021). Sustainable Industrial and Operation Engineering Trends and Challenges toward Industry 4.0: A Data Driven Analysis. J. Ind. Prod. Eng., 1-18. doi:10.1080/21681015.2021.1950227

Wang, C.-N., Ho, H.-X., Luo, S.-H., and Lin, T.-F. (2017). An Integrated Approach to Evaluating and Selecting Green Logistics Providers for Sustainable Development. Sustainability 9, 218. doi:10.3390/su9020218

Wang, D.-F., Dong, Q.-L., Peng, Z.-M., Khan, S., Tarasov, A., and Id, A. T. (2018). The Green Logistics Impact on International Trade: Evidence from Developed 
and Developing Countries. Sustainability 10, 2235-2319. doi:10.3390/ su10072235

Wong, J. K. W., Chan, J. K. S., and Wadu, M. J. (2016). Facilitating Effective green Procurement in Construction Projects: An Empirical Study of the Enablers. J. Clean. Prod. 135, 859-871. doi:10.1016/j.jclepro.2016.07.001

Wong, S. K. S. (2013). Environmental Requirements, Knowledge Sharing and green Innovation: Empirical Evidence from the Electronics Industry in China. Bus. Strat. Env. 22, 321-338. doi:10.1002/bse.1746

Woody, C. (1924). A Survey of Educational Research in 1923. J. Educ. Res. 9, 357-381.

Zailani, S., Amran, A., and Jumadi, H. (2011). Green Innovation Adoption Among Logistics Service Providers in Malaysia: An Exploratory Study on the Managers' Perceptions. Int. Business Management 5, 104-113. doi:10.3923/IBM.2011. 104.113

Zhang, W., Zhang, M., Zhang, W., Zhou, Q., and Zhang, X. (2020). What Influences the Effectiveness of green Logistics Policies? A Grounded Theory Analysis. Sci. Total Environ. 714, 136731. doi:10.1016/j. scitotenv.2020.136731
Conflict of Interest: The authors declare that the research was conducted in the absence of any commercial or financial relationships that could be construed as a potential conflict of interest.

Publisher's Note: All claims expressed in this article are solely those of the authors and do not necessarily represent those of their affiliated organizations or those of the publisher, the editors, and the reviewers. Any product that may be evaluated in this article, or claim that may be made by its manufacturer, is not guaranteed or endorsed by the publisher.

Copyright $(2022$ Sandra Marcelline, Chengang, Ralison Ny Avotra, Hussain, Zonia and Nawaz. This is an open-access article distributed under the terms of the Creative Commons Attribution License (CC BY). The use, distribution or reproduction in other forums is permitted, provided the original author (s) and the copyright owner $(s)$ are credited and that the original publication in this journal is cited, in accordance with accepted academic practice. No use, distribution or reproduction is permitted which does not comply with these terms. 